\title{
Human Clusterin Gene Expression Is Confined to Surviving Cells during In Vitro Programmed Cell Death
}

\author{
Lars E. French, * Annelise Wohlwend, "s André-Pascal Sappino, ${ }^{\star}$ Jürg Tschopp," and Jürg A. Schifferli * \\ Divisions of ${ }^{*}$ Nephrology and ${ }^{\ddagger}$ Oncology, University Hospital of Geneva $;{ }^{\S}$ Institute of Histology and Embryology, University of Geneva \\ School of Medicine, 1211 Geneva; and "Institute of Biochemistry, University of Lausanne, 1066 Epalinges, Switzerland
}

\begin{abstract}
Clusterin is a serum glycoprotein endowed with cell aggregating, complement inhibitory, and lipid binding properties, and is also considered as a specific marker of dying cells, its expression being increased in various tissues undergoing programmed cell death (PCD). However, no study has so far directly shown that cells expressing clusterin in these tissues are actually apoptotic as defined by morphological and biochemical criteria. We have studied cellular clusterin gene expression in vitro using three different models of PCD: (a) ultraviolet B (UV-B) irradiation of human U937, HeLa, and A431 cell lines, (b) in vitro aging of human peripheral blood neutrophils (PMNs), and $(c)$ dexamethasone-induced cell death of the human lymphoblastoid cell line CEM-C7. In all three models, the classical morphological and biochemical features of PCD observed did not correlate with an increase, but with either a marked decrease or an absence of clusterin gene expression as assessed by Northern blot analysis. In situ hybridization of U937 and A431 cells after UV-B irradiation revealed, in addition, that only morphologically normal cells that are surviving continue to express the clusterin gene.

Our results demonstrate that in the human myeloid, lymphoid, and epithelial cell types studied, clusterin gene expression is not a prerequisite to their death by apoptosis. In addition, and most interestingly, in situ hybridization of U937 and A431 cells revealed that only surviving cells express the clusterin gene after the induction of PCD, thus providing novel evidence suggesting that clusterin may be associated with cell survival within tissues regressing as a consequence of PCD. ( $J$. Clin. Invest. 1994. 93:877-884.) Key words: apoptosis • complement $\bullet$ testosterone repressed prostate message- 2 apolipoprotein-J $\cdot$ lipid
\end{abstract}

\section{Introduction}

Clusterin is a heterodimeric glycoprotein originally characterized as a cell aggregating factor produced by Sertoli cells and present in high quantities within ram rete testis fluid $(1,2)$. The human homolog of clusterin was isolated later as a normal

Portions of this work were presented in abstract form at the 1st International Clusterin Workshop, 13-16 September 1992, Cambridge, UK.

Address correspondence to Dr. Lars E. French, Laboratoire d'Immuno-Nephrologie, Centre Medical Universitaire, 1 rue Michel-Servet, 1211 Geneva 4, Switzerland.

Received for publication 31 May 1993 and in revised form 21 September 1993.

J. Clin. Invest.

(C) The American Society for Clinical Investigation, Inc.

$0021-9738 / 94 / 02 / 0877 / 08 \quad \$ 2.00$

Volume 93, February 1994, 877-884 serum protein present within glomerular immune complex and terminal complement deposits of patients suffering glomerulonephritis (3). Further characterization led to the demonstration that clusterin was a novel potent inhibitor of complementmediated cytolysis. Indeed, clusterin could specifically bind to the nascent C5b-6 complex, thus suppressing the cytolytic potential of the membrane attack complex of complement (MAC) ${ }^{1}$ by preventing the association of the complex with the plasma membrane and rendering it soluble (4-6). The co-localization of clusterin with the MAC in kidney diseases, experimental Heymann nephritis, and lupus skin disease suggests that it also participates in the regulation of the terminal complement cascade in vivo (7-10). Human clusterin has also been shown to form a complex with apo A-1 and was independently named NA1 / NA2 or apo J (11-14). Following density ultracentrifugation, these apo A-1/clusterin complexes are found in the slow-migrating HDL fraction of fasting plasma, representing $\sim 5 \%$ of total HDL, and it has been suggested that clusterin might thereby serve as a regulator of lipid transport and of local lipid redistribution $(15,16)$.

Recently, the molecular structure of clusterin has been elucidated by partial amino acid sequencing and cDNA sequencing in several vertebrate species with different phylogenetic distances ranging from the human to the quail (for review see reference 17). The nucleotide sequence of clusterin, as well as its distribution and its level of expression in different tissues has been found to be highly conserved between species, the highest levels of mRNA being detected in the testes, the brain, the adrenal medulla, the liver, the pituitary gland, and the ovary $(14,18,19)$.

Several recent studies have demonstrated an association between clusterin and cell death. Indeed, clusterin mRNA and/ or protein, also known as testosterone-repressed prostate message-2 (TRPM-2), have been shown to be increased in various tissues regressing as a consequence of programmed cell death (PCD), such as in the prostatic epithelial cells after castration (20-23), in the renal collecting ducts and distal tubules after ureteral obstruction $(20,24)$, and in the rat hippocampus after experimental deafferentation (25) (for review see reference 17).

However, no study has so far demonstrated that the individual cells expressing clusterin in tissues undergoing PCD are actually apoptotic as defined by morphological and biochemical criteria (26-28). We have recently shown that human thymocytes undergo PCD during the negative selection process in the absence of clusterin gene expression, whereas in situ hybridization revealed the presence of clusterin mRNA in surrounding nonapoptotic epithelial cells (29). This finding suggested

\footnotetext{
1. Abbreviations used in this paper: $\mathrm{EtBr}$, ethidium bromide; MAC, membrane attack complex; PCD, programmed cell death; SGP-2, sulfated glycoprotein-2; TRPM-2, testosterone-repressed prostate message; UV-B, ultraviolet B.
} 
that clusterin expression was not a prerequisite for the programmed death of thymocytes, and that clusterin is presumably not a death gene in these cells.

To further investigate this hypothesis, we have analyzed five different human cell types for the presence of clusterin mRNA in three different models of PCD, namely, $(a)$ exposure of U937, HeLa, and A431 cell lines to UV-B, $(b)$ in vitro aging of human neutrophils (PMNs), and (c) dexamethasone-induced cell death of the steroid-sensitive lymphoblastoid cell line CEM-C7. The present work demonstrates that, in all cases, PCD ( objectivized by the presence of DNA fragmentation and apoptotic cell morphology) correlates with a marked decrease in clusterin gene expression. Interestingly, analysis by in situ hybridization allowed us to demonstrate that during in vitro PCD clusterin mRNA was present only in morphologically normal cells. This strongly suggests that clusterin is not a cell death gene but, on the contrary, that it might be involved in cell survival within a hostile environment where PCD occurs.

\section{Methods}

Cells and cell culture. Human epidermoid carcinoma A431, human leukemic T cell CEM-C7 (30), and human histiocytic lymphoma U937 cell lines were grown in RPMI 1640 medium (Gibco, Grand Island, NY) supplemented with 5\% (U937) or 10\% (A431, CEM-C7) FCS (Gibco). Human cervix carcinoma HeLa cells were grown in DMEM medium (Gibco) supplemented with $10 \%$ FCS. All media contained $110 \mathrm{IU} / \mathrm{ml}$ penicillin (Gibco) and $110 \mu \mathrm{g} / \mathrm{ml}$ streptomycin (Gibco). These lines were maintained in exponential growth, at $37^{\circ} \mathrm{C}$ in a humidified $5 \% \mathrm{CO}_{2} / 95 \%$ air atmosphere, harvested at subconfluency with EDTA $3 \mathrm{mM} /$ trypsin $0.5 \%$ ( A431, HeLa) and reseeded in fresh medium 24 or $48 \mathrm{~h}$ before each experiment so as to be $\sim 70 \%$ confluent at the start of the experiment.

Isolation of PMNs. PMNs were isolated from fresh buffy coats of normal donors using a Ficoll-Paque gradient (Pharmacia AB, Uppsala, Sweden) and hypotonic erythrocyte lysis with minor modifications brought to the technique described (31). Briefly, the buffy coat obtained from $\sim 400 \mathrm{ml}$ of normal donor blood was diluted 1:1 vol in PBS/EDTA $2 \mathrm{mM}$, mixed gently with 0.25 vol of $4 \%$ Dextran T 500 (Pharmacia AB), left 30 min for erythrocyte sedimentation after which the leukocyte-rich supernatant was collected and centrifuged $10 \mathrm{~min}$ at $200 \mathrm{~g}$. The pellet was resuspended in $9 \mathrm{ml}$ distilled water to lyse erythrocytes, returned to isotonicity after $40 \mathrm{~s}$ by addition of $3 \mathrm{ml} 0.6 \mathrm{M} \mathrm{KCl}$ and of $40 \mathrm{ml} 0.15 \mathrm{M} \mathrm{NaCl}$, centrifuged $10 \mathrm{~min}$ at $350 \mathrm{~g}$, and resuspended in $20 \mathrm{ml}$ PBS/EDTA $2 \mathrm{mM}$. This suspension was layered over $20 \mathrm{ml}$ Ficoll-Paque (Pharmacia AB), centrifuged $30 \mathrm{~min}$ at $350 \mathrm{~g}$, and the PMN-rich (> 98\% pure, > 99\% trypan blue exclusion) pellet recovered, washed twice in PBS/EDTA $2 \mathrm{mM}$, before resuspension at $5 \times$ $10^{6} / \mathrm{ml}$ in RPMI supplemented with $5 \%$ heat-inactivated FCS and incubation at $37^{\circ} \mathrm{C}$ under standard culture conditions.

All manipulations were performed under sterile conditions at $4^{\circ} \mathrm{C}$ to minimize neutrophil activation and aggregation.

Models of PCD. In U937, HeLa, and A431 cells, PCD was induced as described (32), by exposure from above to a 254-nm UV-B source at a distance of $20 \mathrm{~cm}$ for $10 \mathrm{~min}$ at room temperature and then returned to $37^{\circ} \mathrm{C}$ for 4 or $24 \mathrm{~h}$.

PMNs were aged in vitro by placing them in RPMI medium supplemented with $5 \%$ heat-inactivated FCS under standard culture conditions for 4 to $24 \mathrm{~h}$, time 0 corresponding to the time at which freshly isolated PMNs were resuspended in culture medium. Under similar conditions, PMNs have been shown to undergo time-related morphological and biochemical modifications characteristic of PCD (33). PCD was induced in CEM-C7 cells by incubation in the presence of $10^{-6} \mathrm{M}$ dexamethasone (Organon Teknika, Pfaffikon, Switzerland) as described (30), for variable time periods ranging from $30 \mathrm{~min}$ to $96 \mathrm{~h}$.
Histology. Cytospin preparations were performed with cells collected at different time intervals, air-dried, and stained with MayGrünwald-Giemsa combination (Fluka Chemie AG, Buchs, Switzerland) or hematoxylin-eosin. Cell viability was assessed on 200 cells by trypan blue exclusion (Merck AG, Darmstadt, Germany). Microphotographs were taken with a photomicroscope (Carl Zeiss, Oberkochen, Germany), using Kodak Ektachrome T64 color film.

DNA fragmentation analysis. Fragmented DNA was isolated essentially as described (34). Briefly, cells were collected, centrifuged $10 \mathrm{~min}$ at $200 \mathrm{~g}$, lysed for $10 \mathrm{~min}$ in $1 \mathrm{ml}$ hypotonic lysis buffer (Tris $5 \mathrm{mM}, \mathrm{pH}$ 7.4, EDTA $5 \mathrm{mM}$, Triton X-100 0.5\%) and re-centrifuged $15 \mathrm{~min}$ at $13,000 \mathrm{~g}$ to sediment high molecular weight DNA. Supernatants were extracted once in phenol/chloroform (1:1, vol/vol; plus $2 \%$ isoamyl alcohol) and twice in chloroform/isoamyl alcohol (24:1), precipitated overnight at $-20^{\circ} \mathrm{C}$ in $50 \%$ isopropanol $+130 \mathrm{mM} \mathrm{NaCl}$, washed in $70 \%$ ethanol, dried, resuspended in $10 \mu \mathrm{l}$ Tris $10 \mathrm{mM}$, pH 8.1 + EDTA $1 \mathrm{mM}$, and migrated for $3 \mathrm{~h}$ at $30 \mathrm{~V}$ in a $1.2 \%$ agarose minigel containing $30 \mu \mathrm{g} / \mathrm{ml}$ ethidium bromide ( $\mathrm{EtBr}$ ). Samples were not treated with RNAse. Photographs of the gels were taken under UV transillumination with a Polaroid camera.

Plasmid constructions, in vitro transcription, and Northern blot analysis. The clusterin sense and antisense probes were prepared from pGEM-4 ZLI, containing the full-length human clusterin cDNA (35). The chicken GAPDH antisense probe was prepared from pSP64cGAPDH containing the 1.1-kb chicken muscle glyceraldehyde3-phosphate dehydrogenase (GAPDH) cDNA (36), and the human $\beta$-actin antisense probe from pSP64- $\beta$-actin containing the 600 -bp BamH1-EcoR 1 fragment of 3' untranslated human $\beta$-cytoskeletal actin (37). Radiolabeled cRNAs were synthesized by in vitro transcription in the presence of $12.5 \mu \mathrm{M}$ of $\alpha\left[{ }^{32} \mathrm{P}\right] \mathrm{UTP}(400 \mathrm{Ci} / \mathrm{mmol}$; Amersham International, Amersham, UK), or $30 \mu \mathrm{M}\left[{ }^{3} \mathrm{H}\right] \mathrm{UTP}$ and $30 \mu \mathrm{M}\left[{ }^{3} \mathrm{H}\right]-$ CTP (40 and $20 \mathrm{Ci} / \mathrm{mmol}$, respectively; Amersham International). ${ }^{3} \mathrm{H}$-labeled probes were reduced to an average size of 50-100 nucleotides by mild alkaline hydrolysis as previously described (38). Total RNA was extracted as described elsewhere (39). RNAs were denatured with glyoxal, electrophoresed in $1.2 \%$ agarose gels, and transferred overnight onto Hybond nylon membranes (Hybond-H; Amersham International). Prehybridizations, hybridizations, and posthybridization washes were carried out as described (38).

In situ hybridization. Minor modifications were brought to the procedure previously described (38). Cultures of A431 cells and cytospins of U937 cells were performed on poly-L-lysine (Sigma Chemical Co., St. Louis, $\mathrm{MO}$ ) coated microscope slides, fixed in $4 \%$ glutaraldehyde in PBS for 1-5 min, rinsed in PBS, and stored in $70 \%$ ethanol at $4^{\circ} \mathrm{C}$ until analyzed. 0.4-1 $\times 10^{6} \mathrm{cpm}$ of ${ }^{3} \mathrm{H}$-labeled cRNAs were applied to each section in 20-70 $\mu$ l of hybridization mixture. After graded ethanol dehydration, sections were immersed in a 1:1 dilution of NTB-2 emulsion (Eastman Kodak, Co., Rochester, NY) in deionized water. After 12 wk exposure, sections were developed in Kodak D-19 developer, fixed in $30 \% \mathrm{Na}$ thiosulfate, and counterstained with $1 \%$ methylene blue. Hybridizations using the sense cRNA probe were performed as controls of specificity. Microphotographs were taken with a photomicroscope (Carl Zeiss), equipped with an immersion dark-field condenser, using Kodak Ektachrome T64 color film.

\section{Results}

Only surviving cells continue to express the clusterin gene after $U V$ induction of $P C D$. Exposure of cells to UV-B for periods of time ranging from 5 to $30 \mathrm{~min}$ has been shown to induce PCD in myelomonocytic, $\mathrm{T}$ and B-lymphoblastoid as well as preerythroid cell lines, whereas longer periods of exposure lead to cell necrosis (32). In order to evaluate clusterin gene expression in cells of myeloid and epithelial origin dying as a consequence of PCD, we exposed these cells for a short period of time to a source of UV-B. Following a 10-min exposure to 

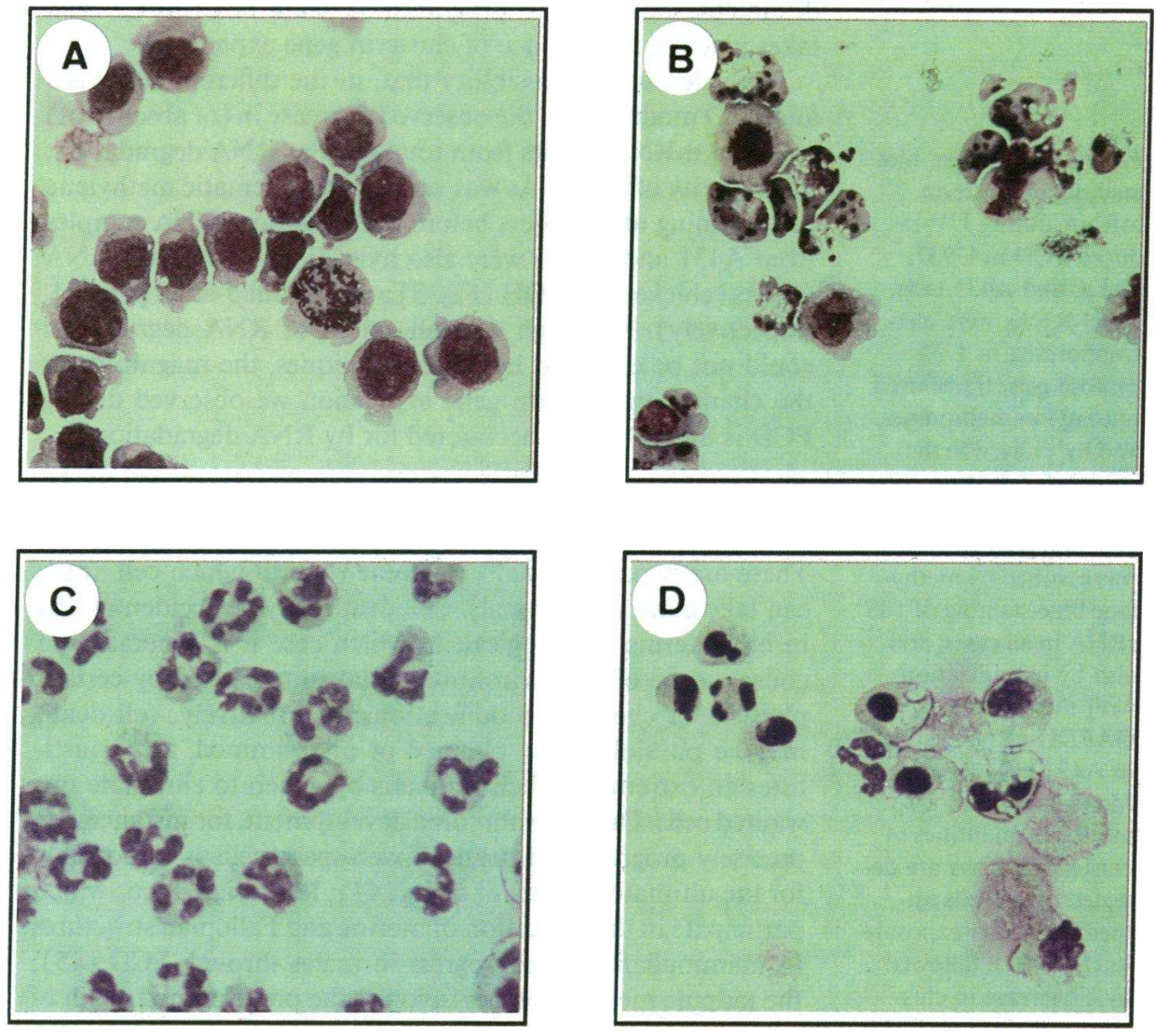

Figure 1. Morphological alterations of U937 cells and PMNs associated with PCD. Cytospin preparations of: $(a)$ U937 cells before $(A)$ and $4 \mathrm{~h}$ after $(B)$ exposure to UV-B, and $(b)$ purified PMNs at the initiation $(C)$ and after $4 \mathrm{~h}(D)$ of in vitro aging. Note the characteristic apoptotic morphology of the cells in $B$ and $D$, as well as the persistence of occasional intact cells after exposure to UV-B. All cytospin preparations were air-dried and subsequently stained by the MayGrünwald-Giemsa technique. ( $A$ and $B, \times 200 ; C$ and $D, \times 370)$

UV-B, most U937 cells develop characteristic signs of apoptosis, including cytoplasmic condensation, nuclear condensation and fragmentation, cellular blebbing, and eventually separation of the cells into clusters of membrane enclosed segments or "apoptotic bodies" (Fig. $1 B$ ). These cells also show marked internucleosomal fragmentation of cellular DNA already $4 \mathrm{~h}$ after UV-exposure (Fig. 2, lane $b$ ). The observed fragmentation ladder of $\sim 180$-bp steps is typical of PCD-associated en-

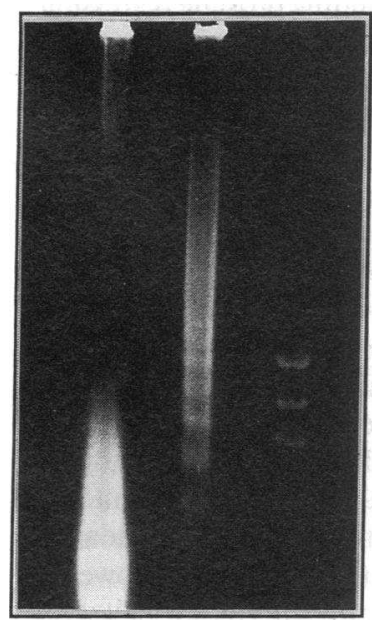

$\mathbf{a}$
$-1353 \mathrm{bp}$ $-1078 \mathrm{bp}$ $-872 \mathrm{bp}$ $-603 \mathrm{bp}$
Figure 2. DNA fragmentation analysis of U937 cells exposed to UV-B. Parallel cultures of U937 cells were exposed for $10 \mathrm{~min}$ to UV-B and their DNA extracted immediately (lane $a$ ) or $4 \mathrm{~h}$ after UV-exposure (lane $b$ ). DNA was then separated on a $1.2 \%$ agarose gel containing $30 \mu \mathrm{g} / \mathrm{ml}$ EtBr and visualized by UV transillumination (see Methods). Clear oligonucleosomal DNA fragmentation was detectable $4 \mathrm{~h}$ after exposure to UV-B. Molecular weight standard: $\phi$ X 174 DNA-Hae III digest (lane $c$ ). dogeneous endonuclease activation and is not the result of direct UV-induced DNA damage, as no fragmentation was detectable immediately after UV irradiation (Fig. 2, lane a). A similar pattern of fragmentation was also observed after exposure of HeLa and A431 cells to UV-B (not shown). Northern blot analysis of total RNA extracted at different time intervals after UV-exposure revealed a marked decrease in clusterin expression in the three cell lines (Fig. 3).

Analysis of U937 cells at different time intervals after UV-B exposure by in situ hybridization revealed little or no clusterin message within apoptotic cells, but considerable levels of clusterin mRNA in surviving cells that were morphologically normal (Fig. 4). Comparison of the autoradiographic labeling of U937 cells at time 0 with that of surviving U937 cells 4 and 24 $h$ after UV exposure did not reveal a significant increase in clusterin message, however. Similar results were obtained with A431 cells analyzed at the time of, or 4 and $24 \mathrm{~h}$ after UV exposure by in situ hybridization (not shown).

Surprisingly, slightly more message was detected by Northern blot analysis in U937 and A431 cells 24 h after UV-exposure, and this could not be explained by the proliferation of cells that may have escaped UV-induced PCD, as the number of morphologically normal cells decreased between 4 and $24 \mathrm{~h}$ (Fig. 5). Northern blots being loaded with $5 \mu \mathrm{g}$ of total RNA at all times tested, the rebound of clusterin mRNA detected at 24 $h$ is relative, presumably due to the fact that apoptotic cells do not contribute to the total RNA any more at this time.

During in vitro aging of human PMNs, clusterin $m R N A$ becomes undetectable. Savill and colleagues had previously shown that PMNs, when extracted from healthy donor blood or inflammatory joints and cultured in vitro, undergo the char- 
U937

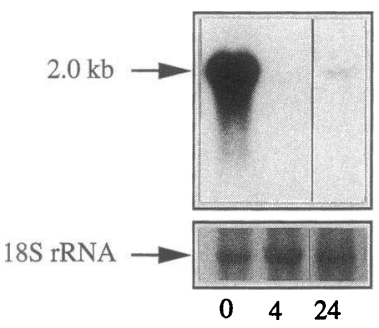

HeLa

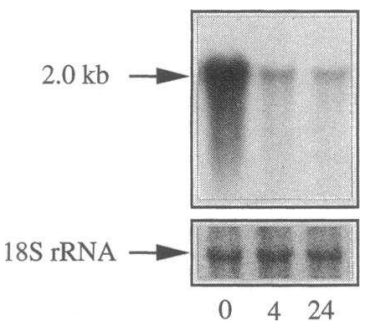

A431

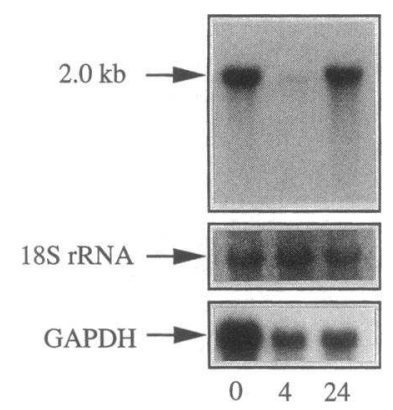

Figure 3. Northern blot analysis of clusterin mRNA during UV-induced PCD in U937, HeLa, and A431 cells. Total RNAs were electrophoresed in $1.2 \%$ agarose gels, transferred onto nylon membranes, and hybridized to the ${ }^{32} \mathrm{P}$-labeled human clusterin cRNA probe $(2.0$ $\mathrm{kb})$. Integrity of RNAs was certified by methylene blue staining of $18 \mathrm{~S}$ rRNA in all cases, and also by hybridization with the chicken GAPDH cRNA probe in A431 cells (see Methods). In all cases, moderate quantities of clusterin mRNA are detected in the cells immediately after exposure to UV-B (0), followed by a decrease in clusterin mRNA 4 and $24 \mathrm{~h}$ after UV-exposure.

acteristic morphological and biochemical modifications of PCD in a time-related manner (33). As this in vitro model of PCD closely resembles the in vivo physiological death of PMNs, it was of interest to evaluate clusterin gene expression in this context. Independent cultures of PMNs isolated from 12 different healthy donors all developed characteristic features of apoptosis (Fig. $1 D$ ), which were already detectable after $4 \mathrm{~h}$ of culture and correlated with chromatin fragmentation (not shown). As illustrated for representative cultures of PMNs (Fig. 6, donors $A$ and $B$ ), Northern blot analysis of total cellular RNA clearly demonstrated that in vitro aging of PMNs correlated with a reduction in the steady-state level of clusterin mRNA in all cultures. Although discrete amounts were still observed after $4 \mathrm{~h}$ in some cultures, clusterin mRNA was undetectable by $24 \mathrm{~h}$ in all cases (Fig. 6).

Dexamethasone-induced $P C D$ in the steroid-sensitive $C E M-C 7$ cell line occurs in the absence of clusterin gene expression. Similarly to cortical thymocytes that classically undergo PCD (40), the human thymus-derived leukemic T-cell CEMC7 line $(30,41,42)$ is known to respond to glucocorticoids, although the kinetics of its response is slightly delayed, signs of PCD being detectable only after $24 \mathrm{~h}(43)$. Northern blot analysis of total RNA from exponentially growing CEM-C7 cells indicated that the clusterin gene is not transcribed in these cells under basal conditions (Fig. 7, time 0 ). When incubated for up to $96 \mathrm{~h}$ in presence of dexamethasone, more than $90 \%$ of CEMC7 cells displayed characteristic signs of apoptosis, whereas their clusterin mRNA remained undetectable at any time tested (Fig. 7). Thus, this result clearly demonstrates that the

dexamethasone-induced programmed death of CEM-C7 cells takes place in the absence of clusterin gene expression.

To rule out the possibility that, in the different cell types and PCD models used, the observed decrease in (or absence of) clusterin mRNA results from total cellular RNA degradation, the integrity of the RNAs was verified by systematic methylene blue staining of the filters before hybridization. RNA samples from A431 and PMNs were also hybridized to control cRNA probes (chicken GAPDH [Fig. 3] and human $\beta$-actin [Fig. 6], respectively). Although a small extent of RNA degradation could not be excluded by these techniques, the magnitude of the changes in clusterin gene expression we observed during PCD is unlikely to be accounted for by RNA degradation.

\section{Discussion}

There are two functionally different ways in which cell death can take place in mammals. Cell death may be accidental and in other terms pathological, in which case it is generally the consequence of an environmental hostility caused by certain physical or chemical modifications. Alternatively, cell death may be physiologically planned or programmed, and constitutes an extremely effective means by which to eliminate unwanted cells. During embryonic development, for instance, the precisely programmed death of web-space cells is responsible for the ultimate shaping of digits (44); Müllerian ducts, which participate in the formation of uterine and Fallopian structures in mammalian females, regress in males through PCD (45); the tadpole metamorphosis involves the programmed death of tail cells $(46,47)$; and the development and differentiation of the vertebrate nervous system requires the PCD-mediated selective elimination of neurons $(48,49)$. In the adult, PCD might also be required in the control of cell growth and proliferation; for instance, the daily elimination of millions of circulating PMNs has been shown to be programmed (33).

Although the exact molecular mechanism by which PCD takes place remains to be elucidated, the requirement of gene transcription and RNA translation for cell death to occur (50, 51 ) strongly argues in favor of an active mechanism. Great interest has recently been given to the search for RNAs specifcally synthesized before or during PCD. One such gene, TRPM-2, has been cloned from regressing rat ventral prostate tissue, and is the rat species homologue of human clusterin (52, 53). Expression of this gene has been shown to be increased in numerous rodent models of $P C D$, including prostate regression after orchiectomy $(20,54)$, cytotoxic tumor regression (20), and renal tubular atrophy during hydronephrosis $(20,21,55)$. Taken together, these observations clearly show that, in whole tissue extracts, PCD is associated with elevated TRPM-2/clusterin levels. However, the major drawback of these studies resides in the lack of information on the functional status of the cells synthesizing clusterin mRNA: Are they cells undergoing PCD, cells that are about to undergo PCD, or cells that escape PCD? To address this question, we have analyzed clusterin gene expression in human cell cultures using three different models of PCD. In all cases, cells were shown to develop characteristic morphological features of PCD, including cytoplasmic and nuclear condensation, cellular blebbing, and nuclear fragmentation, as well as a typical pattern of DNA degradation into oligonucleosome-sized fragments. Surprisingly, however, a rapid and marked decrease in clusterin mRNA was observed in U937, HeLa, and A431 cells undergoing PCD after a short 

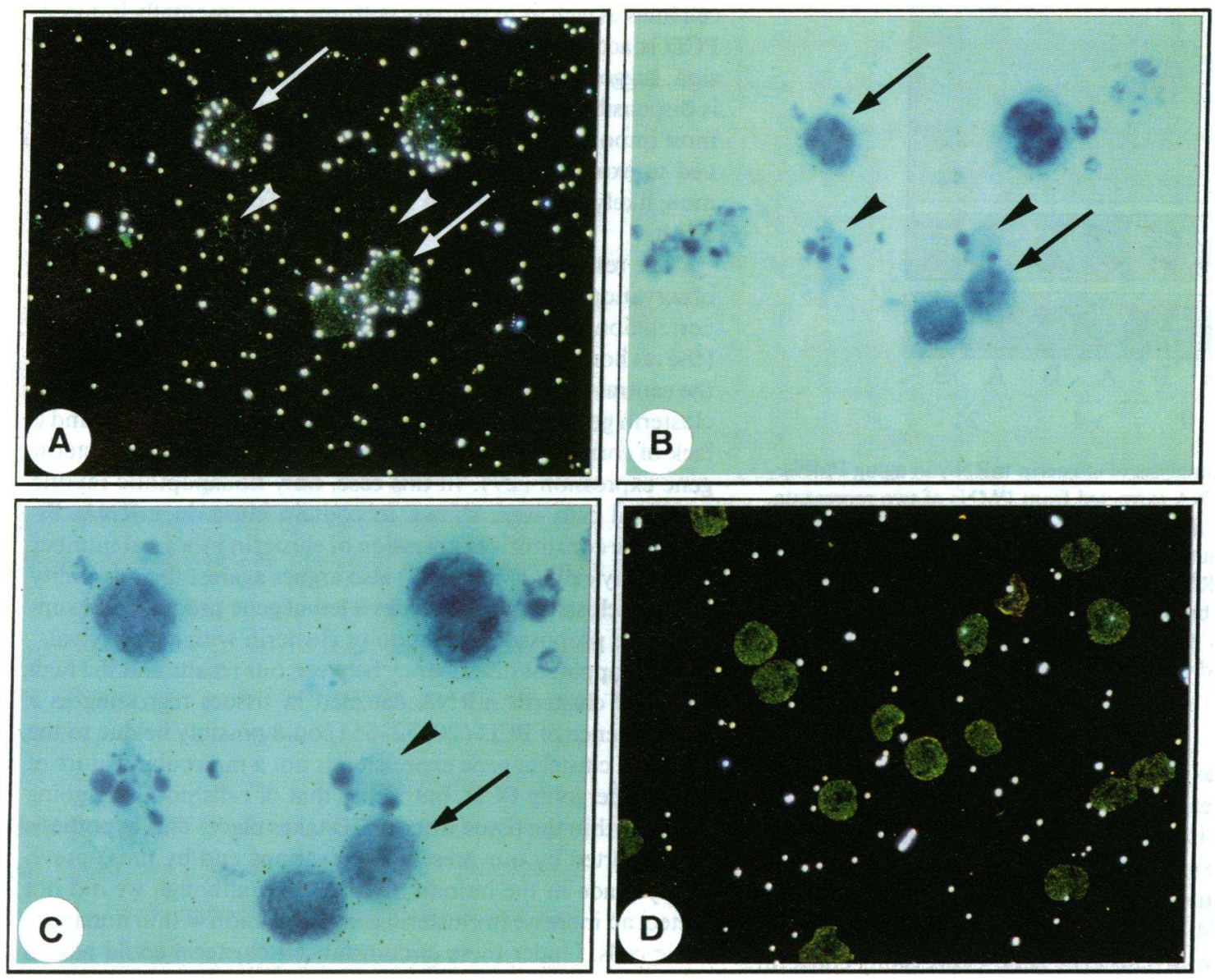

Figure 4. Localization of clusterin mRNA by in situ hybridization of ${ }^{3} \mathrm{H}$-labeled cRNA probes to U937 cells after UV-B induced PCD. $(A)$ is a dark-field micrograph, $(B)$ is the corresponding light-field micrograph, and $(C)$ is a higher magnification of U937 cells $4 \mathrm{~h}$ after induction of PCD by UV-B exposure. Only morphologically normal cells (arrows) that survive the UV-B exposure contain clusterin mRNA, whereas apoptotic cells (arrowheads) contain no detectable message. (D) U937 cells before UV-B exposure hybridized to the sense clusterin cRNA probe. Slides were exposed for 12 wk. ( $A$ and $B, \times 310 ; C \times 500 ; D, \times 160)$.

period of exposure to UV-B. In all three cell lines, the decrease in clusterin mRNA was maximal $4 \mathrm{~h}$ after $\mathrm{UV}$-exposure. In situ hybridization of U937 and A431 cells also revealed a marked decrease in overall clusterin expression 4 and $24 \mathrm{~h}$ after UV exposure, and, in addition, it clearly demonstrated that, in contrast to morphologically preserved surviving cells, which express stable levels of clusterin mRNA, apoptotic cells contained no clusterin mRNA. To exclude the possibility that the

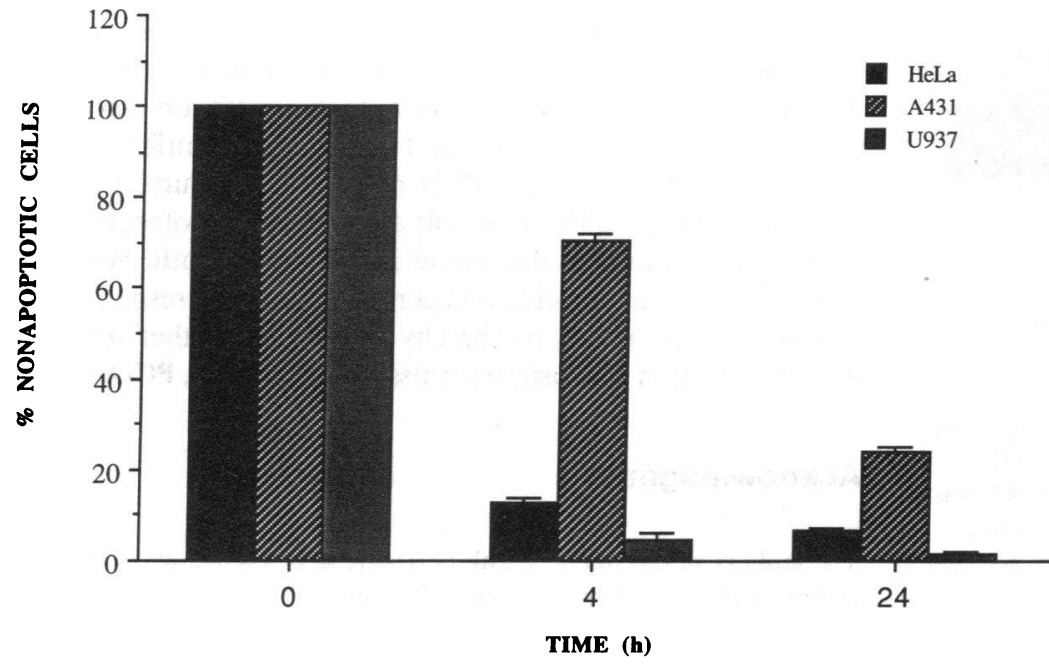

Figure 5. Resistance to UV-B induced PCD of HeLa, A431, and U937 cells in vitro. 0,4 , and $24 \mathrm{~h}$ after UV-B irradiation, cells were collected, directly from culture supernatants in the case of U937 cells, or from culture supernatants and trypsinized monolayers in the case of HeLa and A431 cells. Cytospins were airdried and subsequently stained by the MayGrünwald-Giemsa technique. Based on their morphology, normal and apoptotic cells were counted, and the percentage of normal cells (\% nonapoptotic cells) plotted against the time $(h)$. All percentages were obtained by counting 200 cells per time interval, are the mean of triplicate experiments, and were corrected to take into account overall survival. Morphological evidence of PCD is rapidly apparent in the majority of U937 and HeLa cells by $4 \mathrm{~h}$ and appears delayed in A431 cells. 


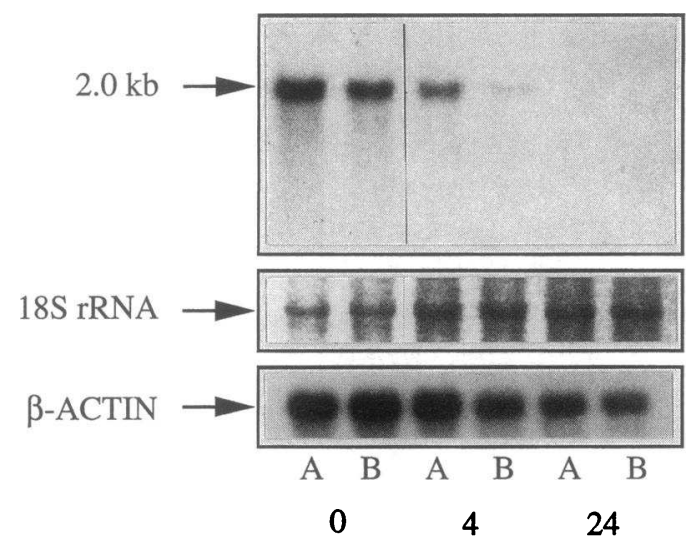

Figure 6. Northern blot analysis of clusterin mRNA in aging PMNs. Northern blot of total RNA extracted from PMNs of two representative donors (lanes $A$ and $B$ ) at different culture intervals, and hybridized to the ${ }^{32} \mathrm{P}$-labeled human clusterin cRNA probe $(2.0 \mathrm{~kb})$ (see Methods). Controls of RNA integrity included methylene blue staining of $18 \mathrm{~S}$ rRNA and hybridization to a 3' UT human $\beta$-actin cRNA probe. Clusterin mRNA decreased rapidly in PMNs undergoing PCD during in vitro aging and became undetectable by $24 \mathrm{~h}$ of aging.

decrease in clusterin expression was only a reflection of UV-induced PCD in cell lines, we also analyzed clusterin gene expression in PMNs freshly isolated from normal human donors and aged in vitro, as these cells have previously been shown to rapidly undergo PCD upon aging in culture, greater than 50\% being apoptotic by $24 \mathrm{~h}(33)$. In these cells also, PCD correlated with a decrease in clusterin gene expression, clusterin mRNA being undetectable by Northern blot analysis after $24 \mathrm{~h}$ of aging. Lastly, in the steroid-sensitive CEM-C7 line, PCD could be completed upon incubation with dexamethasone in the absence of detectable clusterin gene expression.

Taken together, these results demonstrate that in human

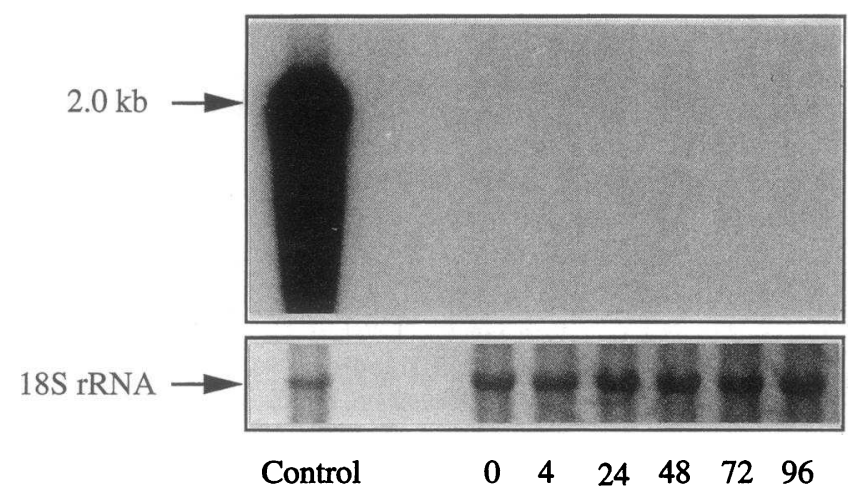

Figure 7. Northern blot analysis of clusterin mRNA during dexamethasone-induced PCD of CEM-C7 cells. Northern blot of total RNA, extracted from CEM-C7 cells incubated for up to $96 \mathrm{~h}$ in the presence of dexamethasone, were hybridized to the ${ }^{32} \mathrm{P}$-labeled human clusterin cRNA probe ( $2.0 \mathrm{~kb}$; see Methods). Methylene blue staining of $18 \mathrm{~S}$ rRNA was used as a control of RNA integrity, and human testis RNA as a positive control (control). No clusterin mRNA was detectable in CEM-C7 cells at the initiation ( 0$)$ or during the subsequent $96 \mathrm{~h}$ of incubation with dexamethasone $(4,24,36,48,60,72$, and 96). cell lines as well as in primary cultures, experimentally induced PCD is accompanied by a reduction of clusterin gene expression, suggesting that clusterin gene expression by the dying cell is dispensible when its death is programmed. In addition, and most importantly, only cells surviving the UV exposure continued to express the clusterin gene, suggesting that clusterin is more likely associated with the process of cell survival than cell death.

The results presented here are in agreement with the recent observation made by Garden et al. demonstrating a lack of correlation between neuronal cell death and neuronal SGP-2 (the rat homologue of human clusterin ) mRNA content within the central nervous system (56). Similarly, in a recent study of clusterin gene expression in the human thymus we also found a lack of correlation between thymocyte apoptosis and clusterin gene expression (29). In this case, only nonapoptotic thymic epithelial cells were shown to contain clusterin mRNA. Finally, the constitutive expression of clusterin by a great number of healthy cells $(1,2,19,57)$ also argues against the possibility that the clusterin gene encodes a lethal gene product, and supports the proposed association of clusterin with cell survival.

The apparent discrepancy between our results and the high levels of clusterin mRNA detected in tissues regressing as a consequence of PCD $(20,52-55)$ could possibly be due to the fact that clusterin gene expression is not a molecular feature of cells undergoing PCD, but rather that of cells not undergoing PCD, within the tissue where PCD takes place. This hypothesis is supported by our present observations and by those previously made in the human thymus (29), although we did not detect an increase in clusterin gene expression within nonapoptotic cells. Under these circumstances, clusterin could have a protective role in a tissue containing cells undergoing PCD; its potent inhibitory activity against complement-mediated cytolysis $(4,5,6,35)$ playing a part in maintaining minimal inflammation. Clusterin has also recently been identified as an HDLassociated protein, quite similar to apoE, a protein that has been shown to be secreted by resident macrophages of the rat sciatic nerve after crush injury and to participate in local cholesterol transport during regeneration and remyelination (58). This similarity, among others, suggests that clusterin secretion by cells not undergoing PCD may, like apoE, help with the removal and redistribution of nonphagocyted membrane lipids originating from apoptotic cells (11-16).

In conclusion, we have demonstrated here that in vitro: $(a)$ cells can undergo PCD in the absence of clusterin gene expression, and $(b)$ clusterin gene expression is confined to morphologically normal and surviving cells after the induction of PCD. We therefore suggest that clusterin gene expression may be associated with cell survival, and that clusterin mRNA detected in tissues undergoing PCD may be that of surrounding cells not undergoing PCD, or cells attempting to protect themselves from conditions that could induce their death. We are currently investigating clusterin gene expression in response to various stresses and hope thereby to provide further insight into the function of clusterin in tissues undergoing PCD.

\section{Acknowledgments}

The authors would like to thank D. Ducrest, B. Baumann, G. Radlgruber, and C. Combépine for technical assistance, Professor G. Gab- 
biani and Dr. M. Pepper for kindly providing the human $\beta$-actin and the GAPDH cDNAs, respectively, Dr. E. B. Thompson for kindly providing the CEM-C7 cell line, as well as J.-C. Rumbeli and J.-P. Gerber for photographic work.

This work was supported by grant numbers 32-32367.91 and 3229289.90 from the Fonds National Suisse pour la Recherche Scientifique, and by the Sandoz foundation. Dr. J. A. Schifferli is the recipient of a Max Cloëtta career development award.

\section{References}

1. Fritz, I. B., K. Burdzy, B. Setchell, and O. Blaschuk. 1983. Ram rete testis fluid contains a protein (clusterin) which influences cell-cell interactions in vitro. Biol. Reprod. 28:1173-1188.

2. Blaschuk, O., K. Burdzy, and I. B. Fritz. 1983. Purification and characterization of a cell-aggregating factor (clusterin), the major glycoprotein in ram rete testis fluid. J. Biol. Chem. 258:7714-7720.

3. Murphy, B. F., L. Kirszbaum, I. D. Walker, and A. J. F. d'Apice. 1988 SP-40,40 a newly identified normal human serum protein found in the SC5b-9 complex of complement and in immune deposits in glomerulonephritis. J. Clin Invest. 81:1858-1864.

4. Choi N.-H., T. Mazda, and M. Tomita. 1989. A serum protein SP40,40 modulates the formation of the membrane attack complex of complement on erythrocytes. Mol. Immunol. 26:835-840.

5. Murphy, B. F., J. R. Saunders, M. K. O'Bryan, L. Kirszbaum, I. D. Walker, and A. J. F. d'Apice. 1989. SP-40,40 is an inhibitor of C5b-6 initiated hemolysis. Int. Immunol. 1:551-554.

6. Choi N.-H., Y. Nakano, T. Tobe, T. Mazda, and M. Tomita. 1990. Incorporation of SP-40,40 into the soluble membrane attack complex (SMAC, SC5b-9) of complement. Int. Immunol. 2:413-417.

7. Eddy, A. A., and I. B. Fritz. 1991. Localization of clusterin in the epimembranous deposits of passive Heymann nephritis. Kidney Int. 39:247-252.

8. Murphy, B. F., D. J. Davies, W. Morrow, and A. J. F. d'Apice. 1989 Localization of terminal complement components, S-protein and SP-40,40 in renal biopsies. Pathology. 21:275-278.

9. French, L. E., L. L. Polla, J. Tschopp, and J. A. Schifferli. Membrane attack complex (MAC) deposits in skin are not always accompanied by S-protein and clusterin. J. Invest. Dermatol. 98:758-763.

10. French, L. E., J. Tschopp, and J. A. Schifferli. Clusterin in renal tissue: preferential localization with the terminal complement complex and Ig deposits in glomeruli. Clin. Exp. Immunol. 88:389-393.

11. Hochstrasser, A. C., R. W. James, B. M. Martin, M. Harrington, D. Hochstrasser, D. Pometta, and C. R. Merril. 1988. HDL particle associated proteins in plasma and cerebrospinal fluid: identification and partial sequencing. Appl. Theor. Electrophor. 1:73-76.

12. De Silva, H. V., W. D. Stuart, Y. B. Park, S. J. T. Mao, C. M. Gil, J. R. Wetterau, S. J. Busch, and J. A. K. Harmony. 1990. Purification and characterization of apolipoprotein J. J. Biol. Chem. 265:14292-14297.

13. De Silva, H. V., W. D. Stuart, C. R. Duvic, J. R. Wetterau, M. J. Ray, D. G. Ferguson, H. W. Albers, W. R. Smith, and J. A. K. Harmony. 1990. A 70-kDa apolipoprotein designated ApoJ is a marker for subclasses of human high density lipoproteins. J. Biol. Chem. 265:13240-13247.

14. De Silva, H. V., J. A. Harmony, W. D. Stuart, C. M. Gil, and J. Robbins. 1990. Apolipoprotein J: structure and tissue distribution. Biochemistry. 29:53805389.

15. James, R. W., A. C. Hochstrasser, I. Borghini, B. Martin, D. Pometta, and D. Hochstrasser. 1991. Characterization of a human high density lipoprotein-associated protein, NA1/NA2. Identity with SP-40,40, an inhibitor of complement-mediated cytolysis. Arterioscler. Thromb. 11:645-652.

16. Jenne, D. E., B. Lowin, M. C. Peitsch, A. Böttcher, G. Schmitz, and J. Tschopp. 1991. Clusterin (complement lysis inhibitor) forms a high density lipoprotein complex with apolipoprotein A-1 in human plasma. J. Biol. Chem. 266:11030-11036.

17. Jenne, D. E., and J. Tschopp. 1992. Clusterin: the intriguing guises of a widely expressed glycoprotein. Trends Biochem. Sci. 17:154-159.

18. Collard, M. W., and M. D. Griswold. 1987. Biosynthesis and molecular cloning of sulfated glycoprotein 2 secreted by rat Sertoli cells. Biochemistry. 26:3297-3303.

19. Hartmann, K., J. Rauch, J. Urban, K. Parczyk, P. Diel, C. Pilarsky, D. Appel, W. Haase, K. Mann, A. Weller, and C. Koch-Brandt. 1991. Molecular cloning of gp 80, a glycoprotein complex secreted by kidney cells in vitro and in vivo. J. Biol. Chem. 266:9924-9931.

20. Buttyan, R., C. A. Olsson, J. Pintar, C. Chang, M. Bandyk, P.-Y. Ng, and I. S. Sawczuk. 1989. Induction of the TRPM-2 gene in cells undergoing programmed death. Mol. Cell. Biol. 9:3473-3481.

21. Bandyk, M. G., I. S. Sawczuk, C. A. Olsson, A. E. Katz, and R. Buttyan.
1990. Characterization of the products of a gene expressed during androgen-programmed cell death and their potential use as a marker of urogenital injury. $J$. Urol. 143:407-413.

22. Grima, J., I. Zwain, R. A. Lockshin, C. W. Bardin, and C. Y. Cheng. 1990 Diverse secretory patterns of clusterin by epididymis and prostate/seminal vesicles undergoing cell regression after orchiectomy. Endocrinology. 126:29892997.

23. Sensibar, J. A., M. D. Griswold, S. R. Sylvester, R. Buttyan, C. W. Bardin, C. Y. Cheng, S. Dudek, and C. Lee. 1991. Prostatic ductal system in rats: regional variation in localization of an androgen-repressed gene product, sulfated glycoprotein-2. Endocrinology. 128:2091-2102.

24. Connor, J., R. Buttyan, C. A. Olsson, V. D'Agati, K. O'Toole, and I. S. Sawczuk. 1991. SGP-2 expression as a genetic marker of progressive cellular pathology in experimental hydronephrosis. Kidney Int. 39:1098-1103.

25. May, P. C., M. Lampert-Etchells, S. A. Johnson, J. Poirier, J. N. Masters, and C. E. Finch. 1990. Dynamics of gene expression for a hippocampal glycoprotein elevated in Alzheimer's disease and in response to experimental lesions in rat. Neuron. 5:831-839.

26. Wyllie, A. H., J. F. R. Kerr, and A. R. Currie. 1980. Cell death: the significance of apoptosis. Int. Rev. Cytol. 68:251-306.

27. Duvall, E., and A. H. Wyllie. 1986. Death and the cell. Immunol. Today. 7:115-119.

28. Wyllie, A. H., R. G. Morris, A. L. Smith, and D. Dunlop. 1984. Chromatin cleavage in apoptosis: association with condensed chromatin morphology and dependence on macromolecular synthesis. J. Pathol. 142:67-77.

29. French, L. E., A.-P. Sappino, J. Tschopp, and J. A. Schifferli. 1992. Distinct sites of production and deposition of the putative cell death marker clusterin in the human thymus. J. Clin. Invest. 90:1919-1925.

30. Norman, M. R., and E. B. Thompson. 1977. Characterization of a glucocorticoid-sensitive human lymphoid cell line. Cancer Res. 37:3785-3791.

31. Newman, S. L., J. E. Henson, and P. M. Henson. 1982. Phagocytosis of senescent neutrophils by human monocyte-derived macrophages and rabbit inflammatory macrophages. J. Exp. Med. 156:430-442.

32. Martin, S. J., and T. G. Cotter. 1991. Ultraviolet B irradiation of human leukemia HL-60 cells in vitro induces apoptosis. Int. J. Radiat. Biol. 59:10011016.

33. Savill, J. S., A. H. Wyllie, J. E. Henson, M. E. Walport, P. E. Henson, and C. Haslett. 1989. Macrophage phagocytosis of aging neutrophils in inflammation. J. Clin. Invest. 83:865-875.

34. Groux, H., G. Torpier, D. Monté, Y. Mouton, A. Capron, and J. C. Ameisen. 1992. Activation-induced death by apoptosis in CD4+ T cells from human immunodeficiency virus-infected asymptomatic individuals. J. Exp. Med. 175:331-340.

35. Jenne, D. E., and J. Tschopp. 1989. Molecular structure and functional characterization of a human complement cytolysis inhibitor found in blood and seminal plasma: identity to sulfated glycoprotein 2 , a constituent of rat testis fluid. Proc. Natl. Acad. Sci. USA. 86:7123-7127.

36. Dugaiczyk, A., H. A. Haron, E. M. Stone, O. E. Dennison, K. N. Rothblum, and R. J. Schwartz. 1983. Cloning and sequencing of a deoxyribonucleic acid copy of glyceraldehyde-3-phosphate dehydrogenase messenger ribonucleic acid isolated from chicken muscle. Biochemistry. 22:1605-1613.

37. Ponte, P., P. Gunning, H. Blau, and L. Kedes. 1983. Human actin genes are single copy for alpha-skeletal and alpha-cardiac actin but multicopy for betaand gamma-cytoskeletal genes: 3 ' untranslated regions are isotype specific but are conserved in evolution. Mol. Cell. Biol. 3:1783-1791.

38. Sappino, A.-P., J. Huarte, J.-D. Vassalli, and D. Belin. 1991. Sites of synthesis of urokinase and tissue-type plasminogen activators in the murine kidney. J. Clin. Invest. 87:962-970.

39. Sappino, A.-P., N. Busso, D. Belin, and J.-D. Vassalli. 1987. Increase of urokinase-type plasminogen activator gene expression in human lung and breast carcinomas. Cancer. Res. 47:4073-4046.

40. Wyllie, A. H. 1980. Glucocorticoid-induced thymocyte apoptosis is associated with endogeneous endonuclease activation. Nature (Lond.). 284:555-556.

41. Kaplan, J., Y. Ravindranath, and W. Peterson. 1977. T and B lymphocyte antigen-positive null cell leukemias. Blood. 49:371-378.

42. Smith, R. W., R. M. Blaese, K. R. Hathcock, D. N. Buell, R. L. Edelson, and M. A. Lutzner. 1974. Lymphocyte Recognition and Effector Mechanisms. K. Lindahl-Kiessling and D. Osoba, editors. Academic Press, Inc., New York. 127-146.

43. Bansal, N., A. G. Houle, and G. Melnykovych. 1989. Comparison of dexamethasone and lovastatin (mevinolin) as growth inhibitors in cultures of T-cell derived human acute leukemia lines (CEM). Leuk. Res. 13:875-882.

44. Saunders, J. W., Jr. 1966. Death in embryonic systems. Science (Wash. DC). 154:604-609.

45. Jost, A. 1970. Hormonal factors in the sex differentiation of the mammalian foetus. Philos. Trans. R. Soc. Lond. Ser B Biol. Sci. 259:119-130.

46. Kerr, J. F., B. Harmon, and J. Searle. 1974. An electron-microscope study of cell deletion in the anuran tadpole tail during spontaneous metamorphosis 
with special reference to apoptosis of striated muscle fibers. J. Cell Sci. 14:571585.

47. Lockshin, R. A. 1981. Cell Death in Biology and Pathology. R. A. Lockshin and I. D. Bowen editors. Chapman and Hall, New York. 79-122.

48. Hamburger, V., and R. Levi-Montalcini. 1949. Proliferation, differentiation and degeneration in the spinal ganglia of the chick embryo under normal and experimental conditions. J. Exp. Zool. 111:457-501.

49. Cowan, W. M., J. W. Fawcett, D. D. M. O'Leary, and B. B. Stanfield. 1984. Regressive events in neurogenesis. Science (Wash. DC). 225:1258-1265.

50. Duke, R. C., and J. J. Cohen. 1986. IL-2 addiction: withdrawal of growth factor activates a suicide program in dependent T cells. Lymphokine Res. 5:289299.

51. Martin, D. P., R. E. Schmidt, P. S. Di Stefano, O. H. Lowry, J. G. Carter, and $\mathrm{E}$. M. Johnson, Jr. 1988. Inhibitors of protein synthesis and RNA synthesis prevent neuronal death caused by nerve growth factor deprivation. J. Cell Biol. 106:829-844.

52. Leger, J. G., M. L. Montpetit, and M. R. Tenniswood. 1987. Characterization and cloning of androgen-repressed mRNAs from rat ventral prostate. Biochem. Biophys. Res. Commun. 147:196-203.
53. Bettuzzi, S., R. A. Hiipakka, P. Gilna, and S. Liao. 1989. Identification of an androgen-repressed $\mathrm{mRNA}$ in rat ventral prostate as coding for sulfated glycoprotein 2 by cDNA cloning and sequence analysis. Biochem. J. 257:293-296.

54. Kyprianou, N., H. F. English, and J. T. Isaacs. 1990. Programmed cell death during regression of PC-82 human prostate cancer following androgen ablation. Cancer Res. 50:3748-3753.

55. Sawczuk, I. S., G. Hoke, C. A. Olsson, J. Connor, and R. Buttyan. 1989. Gene expression in response to acute unilateral ureteral obstruction. Kidney Int. 35:1315-1319.

56. Garden, G. A., M. Bothwell, and E. W. Rubel. 1991. Lack of correspondence between mRNA expression for a putative cell death molecule (SGP-2) and neuronal cell death in the central nervous system. J. Neurobiol. 22:590-604.

57. Burkey, B. F., H. deSilva, and J. A. K. Harmony. 1991. Hepatic apolipoprotein $\mathrm{J}$ is secreted as a lipoprotein. J. Lipid Res. 32:1039-1048.

58. Boyles, J. K., C. D. Zoellner, L. J. Anderson, L. M. Kosik, R. E. Pitas, K. H. Weisgraber, D. Y. Hui, R. W. Mahley, P. J. Gebicke-Haerter, M. J. Ignatius, and E. M. Shooter. 1989. A role for apolipoprotein E, apolipoprotein A-1, and low density lipoprotein receptors in cholesterol transport during regeneration and remyelination of the rat sciatic nerve. J. Clin. Invest. 83:1015-1031. 